\title{
Biomarkers of Cardiometabolic Risk in Obese/Overweight Children: Effect of Lifestyle Intervention
}

\author{
M. VRABLÍK ${ }^{1}$, M. DOBIÁŠOVÁ ${ }^{2}$, L. ZLATOHLÁVEK ${ }^{1}$, Z. URBANOVÁ ${ }^{3}$, R. ČEŠKA $^{1}$ \\ ${ }^{1}$ Third Department of Medicine, First Medical Faculty, Charles University and General Teaching \\ Hospital, Prague, Czech Republic, ${ }^{2}$ Institute of Physiology Academy of Sciences of the Czech \\ Republic, Prague, Czech Republic, ${ }^{3}$ The Children's Clinic, First Medical Faculty, Charles \\ University Prague, Czech Republic
}

Received August 4, 2014

Accepted August 18, 2014

On-line August 26, 2014

\section{Summary}

Obesity is a strong cardiometabolic (CM) risk factor in children. We tested potential $\mathrm{CM}$ risk in obese/overweight children and the effect of an intensive lifestyle intervention using newer CM markers: atherogenic index of plasma AIP [Log(TG/HDL-C)], apoB/apoAI ratio and a marker of insulin resistance HOMA-IR. The participants (194 girls, 115 boys, average age 13) were enrolled in an intensive, one-month, inpatient weight reduction program. The program consisted of individualised dietary changes and the exercise program comprised aerobic and resistance training. Anthropometrical and biochemical parameters in plasma and CM risk biomarkers - (AIP, apoB/apoAI ratio and HOMA-IR) were examined before and after the intervention. AIP and HOMA-IR significantly correlated with BMI while apoB/apoAI ratio did not. Only AIP and HOMA-IR showed systematic increases according to the level of obesity by BMI quartiles. Lifestyle intervention significantly improved anthropometrical and biochemical values and the biomarkers too. The response of lipid parameters to the intervention was considerably higher in boys than in girls. The children were stratified into three risk categories according to AIP, where $13.8 \%$ of boys and $5.3 \%$ of girls fell into high risk category. The monitored biomarkers may complement each other in the prognosis of CM risk. AIP was strongly related to obesity and to lipid and glycid metabolism, while the relationship of the apoB/apoAI ratio to obesity and glycid metabolism was not significant. The obese children benefited from the intensive lifestyle intervention which improved the anthropometrical and biochemical parameters and CM risk biomarkers.

\section{Key words}

AIP [Log(TG/HDL-C)] • ApoB/apoAI ratio • HOMA-IR (insulin resistance) - Cardiometabolic risk markers - Intensive lifestyle intervention • Overweight/obese children

\section{Corresponding author}

M. Dobiášová, Institute of Physiology Academy of Sciences of the Czech Republic, Vídeňská 1083, Prague 4, 142 20, Czech Republic. Fax: +420 24062488. E-mail: dobias@biomed.cas.cz

\section{Introduction}

It is necessary to pay close attention to the prevention of cardiovascular diseases as early as childhood. In children the principal warning signals are obesity and dyslipidemia (Kwiterovich 1991, Canas et al. 2013). In the Czech Republic, $6 \%$ of children suffer from obesity, $9 \%$ are overweight, $23 \%$ have dyslipidemia (Kobzová et al. 2004, Šamánek and Urbanová 2008). However, typical atherogenic risks, such as increased concentration of cholesterol (TC), and triglycerides (TG) and a low high density cholesterol (HDL-C) concentration are not manifested in children as considerably as in adults. Characteristic differences in reduced HDL-C concentration between males and females are not manifested in children either. Only in post-pubescent girls ( $\geq 15$ years), the ratio of the large cardioprotective lipoprotein $\mathrm{HDL}_{2 b}$ particles to $\mathrm{HDL}$ lipoproteins increases first, while remains unchanged in boys (Dobiášová et al. 1998). Therefore, it is justifiable

PHYSIOLOGICAL RESEARCH • ISSN 0862-8408 (print) • ISSN 1802-9973 (online)

(c) 2014 Institute of Physiology v.v.i., Academy of Sciences of the Czech Republic, Prague, Czech Republic

Fax +420 241062 164, e-mail: physres@biomed.cas.cz, www.biomed.cas.cz/physiolres 
to look for more sensitive biomarkers for the future prognoses of children.

Recently, the predictive importance of AIP (Dobiášová and Frohlich 2001, Frohlich and Dobiášová 2003, Onat et al. 2010, Dobiášová et al. 2011) and apoB/apoAI ratio (Walldius et al. 2001, Thompson and Danesh 2006) as biomarkers of cardiovascular diseases has been confirmed, reflecting the balance between risk and protective biomarkers (TG and HDL-C in AIP; LDL and HDL in apoB/apoAI ratio). Both biomarkers correspond to specific sub-populations of HDL and LDL lipoproteins that vary in density, and size and different atherogenic potentials. Small dense LDL particles are distinctively atherogenic (Campos et al. 1992) relative to large LDL particles. In contrast, large particles are strongly atherogenic among the VLDL sub-populations. Sub-populations of HDL also have different atherogenic potentials: large particles are more protective than the smaller ones (Jeyarajah et al. 2006). The atherogenic profile of plasma is thus defined by a summary of risk factors reflected in the structure of lipoprotein subpopulations and, thus, also in the AIP and apoB/apoAI biomarkers. Therefore, both AIP and apoB/apoAI carry greater predictive value than the concentrations of individual lipid parameters and can be used as risk biomarkers in the case of relatively normal concentrations of plasmatic lipids. Insulin resistance (as indicated HOMA-IR - homeostatic model assessment-insulin resistance) together with obesity represents another respected and significant CM marker (Reaven 2012).

The objective of this study was to determine the success of the $\mathrm{CM}$ biomarkers, AIP, apoB/apoAI ratio and HOMA-IR in overweight/obese children and to identify the types of relationships among these biomarkers and other CM risk parameters. Another area of focus was the frequency of risk values of those biomarkers in a monitored population of girls and boys who had been through an intensive lifestyle intervention.

\section{Patients and Methods}

\section{Patients}

Between June 2009 and March 2011, 309 overweight/obese children between 8 and 15 years of age participated in the study. Overweight was defined as a $\mathrm{BMI} \geq 85$ th- $<95$ th percentile and obesity was defined as a BMI $\geq 95$ th percentile for children of the same age and sex. Exclusion criteria comprised known diabetes mellitus, arterial hypertension, smoking, use of any medications and contraindication of prescribed physical activity. All participants were of Caucasian ethnicity, and written informed consent was given by the parents/guardians of all individuals. The study was approved by the institutional ethics committee and conducted according to good clinical practice guidelines. Patients, intervention and measurements were described in more detail previously (Motykova et al. 2011).

\section{Intervention, anthropometric measurements}

The intervention program consisted of individualised diet changes made to achieve a caloric intake of 5,000 kJ for the age category of 8 to 10 years old and 7,000 kJ for those 11 to 15 years old. The exercise program consisted of aerobic and resistance training ( 5 units, daily, 50 min each) complemented with ball games, swimming, dancing and fast walking. All participants underwent a thorough physical examination. Body weight was measured with a calibrated electronic weight scale. Height was measured to the nearest $0.5 \mathrm{~cm}$. Waist and hip circumferences were also measured with an accuracy of $0.5 \mathrm{~cm}$. BMI $\left(\mathrm{kg}\right.$ per $\left.\mathrm{m}^{2}\right)$ was calculated from obtained measurements. Diastolic and systolic blood pressures were measured after $10 \mathrm{~min}$ in a sitting position with an automated blood pressure unit (Automated sphygmomanometer BP-203 NA, Nippon Colin co., Ltd). Total body fat was determined by impedance analysis using a Bodystat analyser (1500 MDD, Bodystat, Isle of Man, UK).

\section{Biochemical analyses}

Venous blood was collected after $12 \mathrm{~h}$ of fasting and plasma lipid levels, insulin and glycemia were assessed by enzymatic methods using automated analysers (Hitachi, Japan). The LDL-C level was calculated by the Friedewald equation [LDL-C = TC - HDL-C - TG/2.2].

Measurement of the CM risk biomarkers AIP, apoB/apoAI and HOMA-IR

AIP was calculated as a common logarithm of the ratio of molar concentrations of plasma triglycerides and HDL cholesterol AIP was used to stratify children according to their atherogenic risk level. Optionally, as previously described (Rašlová et al. 2011, www.biomed.cas.cz/fgu/aip), AIP values under 0.1 were defined characteristic of low risk, while values corresponding to for medium risk ranged from 0.11 to 0.21 and values over 0.21 were considered characteristic 
of high risk. ApoB/apoAI ratio is a biomarker of cardiovascular risk introduced as a result of a prospective study called AMORIS by Walldius and others (Walldius et al. 2001). The Insulin Resistance HOMA-IR was calculated as ratio of plasma insulin to glycemia divided by 22.5 (Tresaco et al. 2005).

\section{Statistical methods}

Statistical analysis including the following evaluations, was performed using SPSS 15.0. The data are presented as the means \pm SD both before and after intervention for each group. For descriptive purposes, the differences between measurements taken before and after treatment were tested by paired t-test. Differences between genders were tested by independent-samples t-test of initial variables with a $95 \%$ confidence interval. To investigate the correlations between variables, we used Pearson's correlation tested for the equality of two interdependent coefficients by Bonferroni's correction method of significance levels. The variables use to define AIP, apoB/apoAI and HOME-IR were not included in correlation analysis to avoid co-linearity problems.

\section{Results}

Characteristics of the group and influence of intensive lifestyle intervention

Statistically important differences in anthropometric values were found between boys and girls (Table 1). As expected, boys were considerably taller and heavier than girls $(+8.7 \mathrm{~cm}$ and $+13.7 \mathrm{~kg})$. The boys also had higher BMI values (31.7) than girls (30.1). The initial value of systolic pressure was slightly significantly higher in boys, while the values of diastolic pressure did not vary significantly. Waistline, abdomenline and hipline were larger in boys. Initial biochemical values did not vary depending on sex, and only one significance was found - lower apoAI and HDL-C in boys (Table 2).

Table 1. Anthropometric characteristics of the children before (1) and after (2) lifestyle intervention: gender differences.

\begin{tabular}{|c|c|c|c|c|c|c|c|c|}
\hline & & \multicolumn{3}{|c|}{ Girls } & \multicolumn{3}{|c|}{ Boys } & \multirow{2}{*}{$\begin{array}{c}\text { G. vs. B. } \\
\mathbf{p}<\end{array}$} \\
\hline & & $\mathbf{n}$ & Mean \pm SD & Red. \% & $\mathbf{n}$ & Mean \pm SD & Red. \% & \\
\hline Age, years & & 194 & $13.0 \pm 2.1$ & & 115 & $13.5 \pm 1.9$ & & $*$ \\
\hline Height, cm & & 197 & $158.6 \pm 9.8$ & & 118 & $167.3 \pm 11.3$ & & $* * *$ \\
\hline Weight, kg & 1 & 197 & $75.3 \pm 17.3$ & & 118 & $89.0 \pm 21.1$ & & $* * *$ \\
\hline Weight, kg & 2 & 190 & $69.9 \pm 16.3 * * *$ & -7.5 & 111 & $81.6 \pm 18.3 * * *$ & -8.2 & $* * *$ \\
\hline$B M I, \mathrm{~kg} / \mathrm{m}^{2}$ & 1 & 195 & $30.1 \pm 4.4$ & & 117 & $31.7 \pm 4.3$ & & $* *$ \\
\hline$B M I, \mathrm{~kg} / \mathrm{m}^{2}$ & 2 & 187 & $27.9 \pm 4.1 * * *$ & -7.4 & 112 & $29.2 \pm 4.2 * * *$ & -8.0 & $*$ \\
\hline$B P_{\text {Systolic }}, m m ~ H g$ & 1 & 192 & $120.9 \pm 15$ & & 117 & $125.1 \pm 13.2$ & & $*$ \\
\hline$B P_{\text {Systolic }}, \mathrm{mm} \mathrm{Hg}$ & 2 & 187 & $117.1 \pm 13 * * *$ & -2.9 & 112 & $121.8 \pm 14.6^{* *}$ & -2.5 & $* *$ \\
\hline$B P_{\text {Diastolic }}, \mathrm{mm} \mathrm{Hg}$ & 1 & 192 & $76.8 \pm 10.9$ & & 117 & $78.2 \pm 10.8$ & & \\
\hline$B P_{\text {Diastolic }}, \mathrm{mm} \mathrm{Hg}$ & 2 & 187 & $73.7 \pm 10 * * *$ & -3.8 & 112 & $73.1 \pm 8.4^{* *}$ & -6.3 & \\
\hline Waist circ., $\mathrm{cm}$ & 1 & 189 & $86.4 \pm 10.6$ & & 110 & $95.9 \pm 11.1$ & & $* * *$ \\
\hline Waist circ., $\mathrm{cm}$ & 2 & 183 & $81.0 \pm 10.4 * * *$ & -6.1 & 104 & $88.9 \pm 10.1 * * *$ & -7.1 & $* * *$ \\
\hline Abdominal c., $\mathrm{cm}$ & 1 & 196 & $98.9 \pm 11.1$ & & 118 & $107.1 \pm 12.1$ & & $* * *$ \\
\hline Abdominal c., $\mathrm{cm}$ & 2 & 190 & $93.1 \pm 11.2 * * *$ & -5.8 & 112 & $99.8 \pm 11.1 * * *$ & -6.6 & $* * *$ \\
\hline Hip, cm & 1 & 196 & $101.4 \pm 11.4$ & & 118 & $106.0 \pm 10.4$ & & $* * *$ \\
\hline Hip, cm & 2 & 190 & $96.1 \pm 11.3^{* * *}$ & -5.3 & 112 & $99.7 \pm 10.2 * * *$ & -6.0 & $* *$ \\
\hline Total body fat, $\%$ & 1 & 183 & $33.2 \pm 13.2$ & & 107 & $32.0 \pm 10.2$ & & \\
\hline Total body fat, $\%$ & 2 & 161 & $30.1 \pm 12.9 * * *$ & -7.2 & 92 & $26.6 \pm 9.7 * * *$ & -15.0 & $*$ \\
\hline
\end{tabular}

Mean \pm SD, significance of differences between initial (1) and final (2) values: $* \mathrm{p}<0.05, * * \mathrm{p}<0.01, * * * \mathrm{p}<0.001, \mathrm{Red} . \%-$ reduction of the initial values in percentage, G. vs. B. - significant differences of values between girls and boys. 
Table 2. Biochemical variables of girls and boys before (1) and after (2) lifestyle intervention: gender differences.

\begin{tabular}{|c|c|c|c|c|c|c|c|c|}
\hline & & \multicolumn{3}{|c|}{ Girls } & \multicolumn{3}{|c|}{ Boys } & \multirow[t]{2}{*}{ G. vs. B. } \\
\hline & & $\mathbf{n}$ & Mean \pm SD & Red. \% & n & Mean \pm SD & Red. \% & \\
\hline$T C, \mathrm{mmol} / \mathrm{l}$ & 1 & 194 & $4.65 \pm 1.01$ & & 118 & $4.44 \pm 0.81$ & & \\
\hline TC, mmol/l & 2 & 184 & $3.79 \pm 0.81 * * *$ & -18.1 & 110 & $3.33 \pm 0.67 * * *$ & -24.8 & $* * *$ \\
\hline$T G, \mathrm{mmol} / \mathrm{l}$ & 1 & 190 & $1.05 \pm 0.47$ & & 117 & $1.11 \pm 0.60$ & & \\
\hline$T G, \mathrm{mmol} / \mathrm{l}$ & 2 & 182 & $0.84 \pm 0.32^{* * *}$ & -18.5 & 109 & $0.78 \pm 0.31 * * *$ & -30.1 & \\
\hline$L D L-C, \mathrm{mmol} / \mathrm{l}$ & 1 & 193 & $2.85 \pm 0.82$ & & 118 & $2.71 \pm 0.71$ & & \\
\hline$L D L-C, \mathrm{mmol} / \mathrm{l}$ & 2 & 185 & $2.24 \pm 0.69 * * *$ & -21.4 & 110 & $1.87 \pm 0.60 * * *$ & -30.5 & $* * *$ \\
\hline$H D L-C, \mathrm{mmol} / \mathrm{l}$ & 1 & 193 & $1.31 \pm 0.28$ & & 118 & $1.24 \pm 0.28$ & & $*$ \\
\hline$H D L-C, \mathrm{mmol} / \mathrm{l}$ & 2 & 185 & $1.16 \pm 0.23 * * *$ & -11.6 & 110 & $1.08 \pm 0.26 * * *$ & -12.8 & $*$ \\
\hline Glycemia, mmol/l & 1 & 191 & $4.93 \pm 0.40$ & & 117 & $5.03 \pm 0.46$ & & \\
\hline Glycemia, mmol/l & 2 & 184 & $4.96 \pm 0.37$ & 0.5 & 109 & $4.94 \pm 0.37$ & -2.0 & \\
\hline C-peptid, ng/ml & 1 & 181 & $0.86 \pm 0.32$ & & 117 & $0.88 \pm 0.31 * * *$ & & \\
\hline C-peptid, $n g / m l$ & 2 & 170 & $0.76 \pm 0.27 * * *$ & -11.7 & 101 & $0.76 \pm 0.29$ & -13.8 & \\
\hline Insulin, mlU/l & 1 & 180 & $15.59 \pm 8.73$ & & 117 & $15.30 \pm 8.01$ & & \\
\hline Insulin, mlU/l & 2 & 168 & $11.89 \pm 6.44 * * *$ & -23.6 & 101 & $11.59 \pm 7.57 * * *$ & -23.5 & \\
\hline apoAI, mmol/l & 1 & 130 & $1.34 \pm 0.19$ & & 73 & $1.28 \pm 0.17$ & & $*$ \\
\hline apoAI, mmol/l & 2 & 120 & $1.17 \pm 0.17 * * *$ & -12.2 & 66 & $1.06 \pm 0.17 * * *$ & -17.0 & $* * *$ \\
\hline apoB, mmol/l & 1 & 129 & $0.90 \pm 0.26$ & & 73 & $0.88 \pm 0.22$ & & \\
\hline apoB, mmol/l & 2 & 119 & $0.76 \pm 0.22 * * *$ & -15.0 & 66 & $0.65 \pm 0.19 * * *$ & -27.2 & $* *$ \\
\hline \multicolumn{9}{|l|}{ CM markers } \\
\hline$A I P$ & 1 & 190 & $-0.124 \pm 0.212$ & & 117 & $-0.084 \pm 0.257$ & & \\
\hline$A I P$ & 2 & 182 & $-0.159 \pm 0.183^{* *}$ & & 109 & $-0.161 \pm 0.221^{* * *}$ & & \\
\hline ароB1/ароAI & 1 & 130 & $0.67 \pm 0.21$ & & 73 & $0.70 \pm 0.20$ & & \\
\hline аров2/ароAI & 2 & 120 & $0.65 \pm 0.21$ & & 66 & $0.62 \pm 0.19 * * *$ & & \\
\hline HOMA-IR & 1 & 115 & $3.48 \pm 2.17$ & & 115 & $3.46 \pm 0.92$ & & \\
\hline$H O M A-I R$ & 2 & 162 & $2.64 \pm 1.53^{* * *}$ & & 162 & $2.56 \pm 1.84 * * *$ & & \\
\hline
\end{tabular}

Mean $\pm S D$, significance of differences between initial (1) and final (2) values: $* p<0.05, * * p<0.01, * * * p<0.001$, Red. $\%-$ reduction of the initial values in percentage, G. vs. B. - significant differences of values between girls and boys.

The lifestyle intervention resulted in a significant reduction of all anthropometric parameters (Table 1). Weight and BMI were reduced in both sexes by $8 \%$, and the waistline, abdomenline and hipline measurements were reduced by approximately $6 \%$. The average percentage of fat was reduced by $15 \%$ in boys, but only by $7 \%$ in girls. Both systolic and diastolic pressure was significantly lowered.

Statistically significant changes occurred in biochemical parameters (Table 2). The test of differences before and after the intervention was significant in the most tested variables $(p<0.001)$, with the exception of glycemia in both sexes and the apoB/apoAI ratio in girls. TC, TG, LDL-C, and apoB levels were reduced by $15-20 \%$ in girls and by $25-30 \%$ in boys. The concentrations of HDL-C and apoAI were reduced in all children after the intervention. In both sexes, C-peptide dropped by $13 \%$ and, insulin by $23 \%$, however, there was no change in glycemia. The AIP values were reduced in both sexes, while the apoB/apoAI biomarker was statistically significantly reduced only in boys. The reduction of HOMA-IR was significant in both sexes (Table 2). 


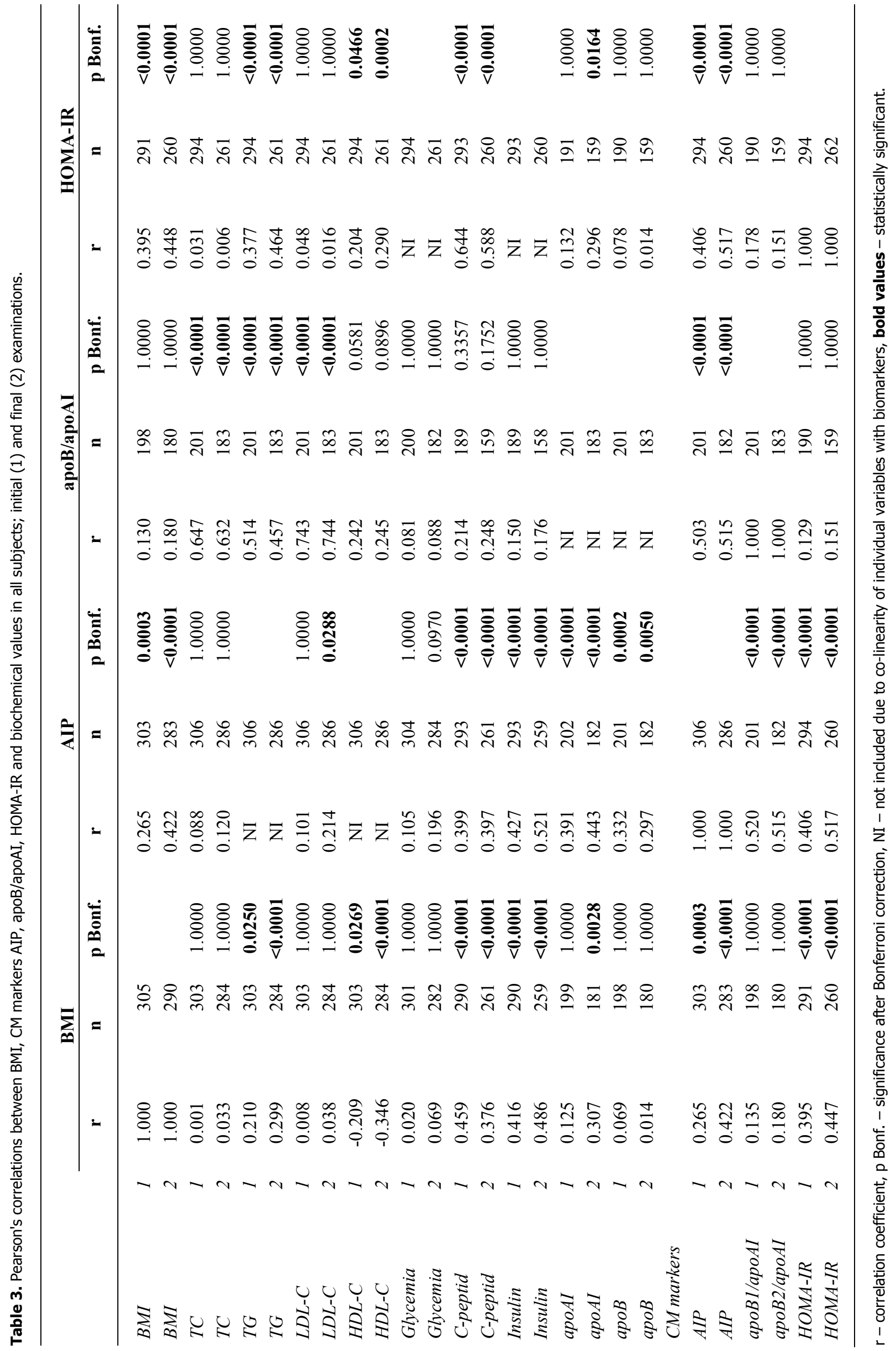


The relation between obesity and biochemical parameters

The correlation analysis (Table 3) showed a strong relation among the initial and final values of BMI and the concentration of plasma TG, HDL-C and AIP. Associations between BMI and total cholesterol, LDL-C and apoprotein B levels were not statistically significant. The inverse correlation between BMI and apoAI was significant only between the values after the intervention. Despite the important connection found between BMI and C-peptide, and insulinemia and HOMA-IR, glycemia was not influenced.

AIP strongly correlated with BMI, C-peptide, insulin and HOMA-IR, both apoproteins and apoB/apoAI ratio. Unlike the apoB/apoAI ratio, AIP was not correlated with the concentration of $\mathrm{TC}$ or the initial values with LDL-C. In contrast, the apoB/apoAI ratio was very strongly correlated with the lipid components, namely with TC, LDL-C and TG. HOMA-IR was significantly correlated with obesity, TG, HDL-C and AIP, while its relationships to TC and LDL-C were not significant. The relationships between the BMI and CM markers confirmed the distribution of values into BMI quartiles, where AIP and HOMA-IR in the BMI quartiles showed a systematic increase according to the obesity grad, while differences in the apoB/apoAI ratio bordered on statistical discrepancy (Fig. 1).

\section{Stratification of children according to the AIP criteria}

The children's initial data were divided into three AIP categories, according to the importance of atherogenic risk (Fig. 2) specified for the adult population (Methods). A total of $84.7 \%$ of girls and $74.1 \%$ of boys fell into the low-risk category (AIP $\leq 0.1), 10 \%$ of girls and $12.1 \%$ of boys fell into the medium-risk category (AIP between 0.11-0.21), and the high-risk category (AIP $>0.21$ ) included $5.3 \%$ of girls and $13.8 \%$ of boys.

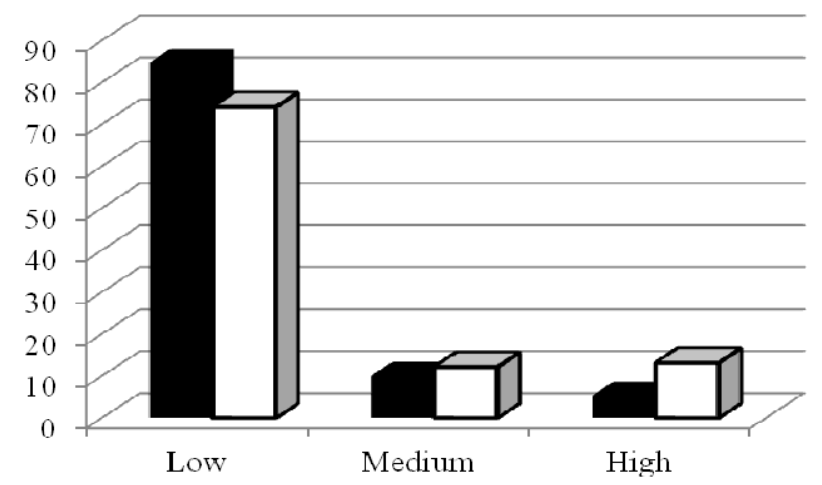

Fig. 2. Classifying children into risk categories according to AIP in \%. AIP risk: Low $\leq 0.10$, Medium 0.11-0.21, High $>0.21$. Girls - full columns, boys - open columns.
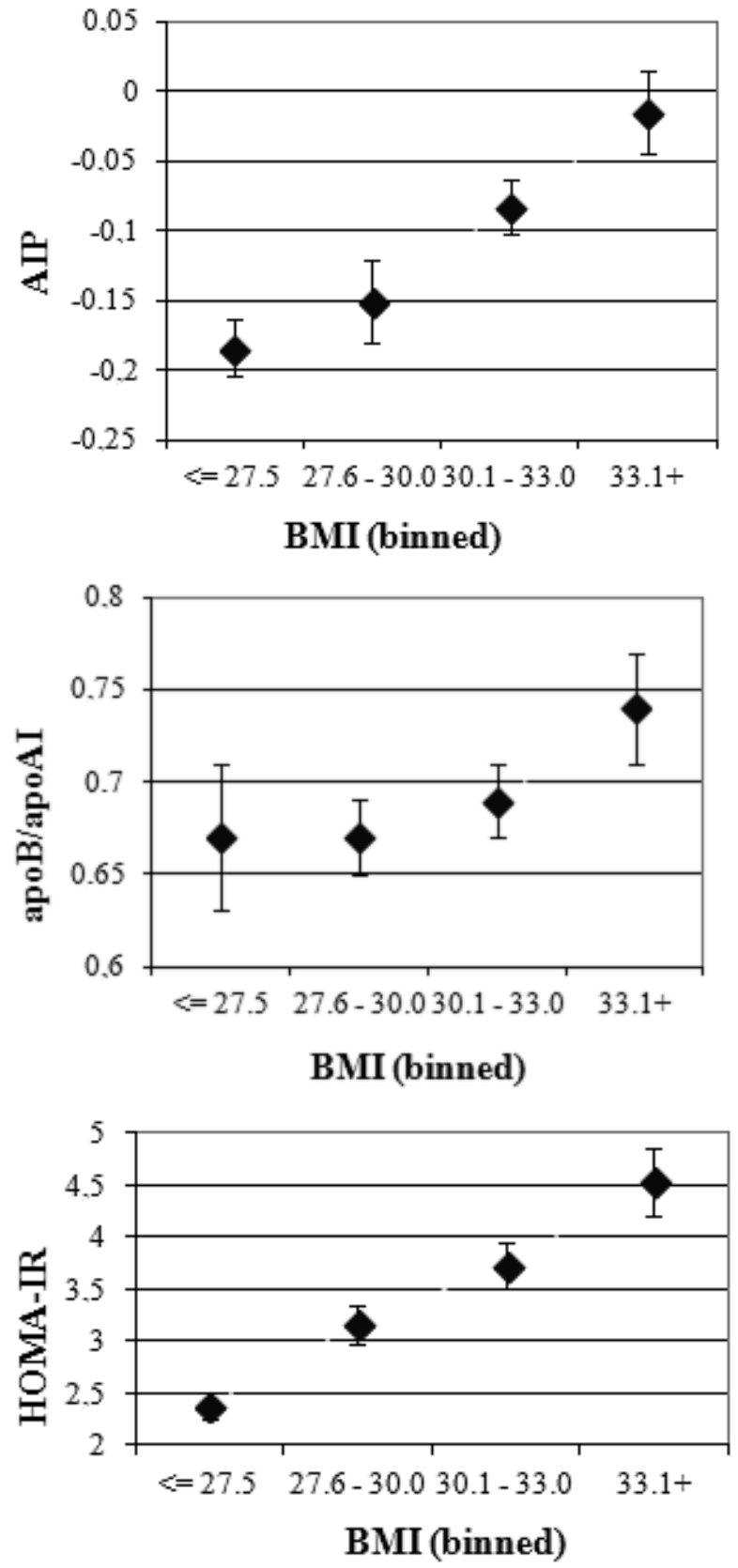

Fig. 1. Initial values (mean $\pm S E$ ) of $A I P$, apoB/apoAI ratio and HOMA-IR in BMI quartiles.

\section{Discussion}

The objective of the study was to examine cardiometabolic risk in overweight/obese children using the CM biomarkers AIP, apoB/apoAI ratio and the HOMA-IR. The children took part in an intensive lifestyle intervention project during a month-long spa treatment. In addition to the usually examined anthropometrical and biochemical parameters, we analyzed the influence of sex on the initial values and on the effect of the intervention. We studied the relationships 
among the children's obesity, both biomarkers and insulin resistance that plays an important role in pathogenesis of coronary heart disease in non-diabetic individuals (Reaven 2012). Boys had higher values of anthropometrical parameters than girls, with the exception of diastolic pressure (Table 1). In contrast, the initial biochemical values of girls and boys exhibited no significant differences, with the exception of slightly higher concentrations of apoAI and HDL-C in girls than in boys. During the intervention, the typically measured anthropometrical parameters improved, and the blood pressure decreased slightly but significantly. However, the intervention produced a significant difference between the sexes because the reaction of certain variables to diet and exercise was stronger in boys than in girls. The reduction of TG, LDL-C, apoB was significantly higher in boys, while the reductions of HDL-C and insulin were at the same level (Table 2). The intervention also caused a reduction in the concentration of HDL-C and apoAI because of the substantial reduction of the total cholesterol. Glycemia remained unchanged, while C-peptide exhibited a reduction of $13 \%$ and insulin and HOMA-IR decreased by $23-25 \%$ in both sexes.

Three CM biomarkers whose importance had been confirmed by a number of studies in adults were studied in parallel within the project. The importance of the association of TG with HDL-C in relation to obesity and CM risk in children had already appeared in the study by Bogalusa (Kikuchi et al. 1992) and other studies had also confirmed the importance of the TG/HDL-C ratio and insulin resistance for the identification of $\mathrm{CM}$ risk (Musso et al. 2011). As "an estimate of small, dense lowdensity lipoprotein cholesterol" TG/HDL-C was described as ,an independent determinant of arterial stiffness in adolescents and young adults, especially in obese youth“ (Murguía-Romero et al. 2013). In our studies, AIP is used as a logarithmically transformed TG/HDL-C ratio because the transformed value produces higher correlations and normal probability plots (Tan et al. 2004). Thus, it is more suitable from the statistical perspective than the simple TG/HDL-C ratio (Urbina et al. 2011).

Another important CM marker - apoB/apoAI ratio reported in the AMORIS study was also described in children as a predictor of cardiovascular risk (Sellers et al. 2009) and insulin resistance (Sierra-Johnson et al. 2007) as a predictor of carotid media thickness and brachial endothelial function in adulthood (Juonala et al. 2008).
In our study, we compared children's obesity with selected biomarkers as a primary $\mathrm{CM}$ risk factor. AIP was significantly correlated with BMI (initial $\mathrm{r}=0.265, \mathrm{p}<0.0003$, final $\mathrm{r}=0.422, \mathrm{p}<0.0001$ ), and the categorisation into BMI quartiles indicated a systematic increase of AIP and HOMA-IR according to the obesity grades (Fig. 1). AIP showed an equally strong association with elements of both lipid and glycid metabolism when the correlation coefficient between AIP and HOMA-IR was high (initial $r=0.406$, final $r=0.517, p<0.0001$ ). The correlation between AIP and the studied parameters was also significant (Table 3). In children, a significant relation of AIP was not found among the main predictors of $\mathrm{CM}$ risk in adults, i.e. TC and LDL-C, even if the relation to apoB (a LDL component) was significant.

The associations between the apoB/apoAI ratio and BMI and HOMA-IR were not statistically significant, while the correlations with TC, LDL-C and TG were highly significant. However, the relationship between the AIP and apoB/apoAI ratio biomarkers before and after the intervention $(p<0.0001)$ was very strong, possibly because both biomarkers are related to lipoprotein particle size. The values of the apoB/apoAI ratio between the BMI quartiles (0.67-0.74) were lower than in a study examining the levels of lipids and apolipoproteins in adult Swedish, Iranian and American populations showed that the average normal value of apoB/apoAI ratio ranged between 0.80 and 0.92 (Solhpour et al. 2009). In our study, the relation of apoB/apoAI to glycid metabolism exhibited lower intensity than in other populations (Sierra-Johnson et al. 2007) because the children had lower concentrations of TC and LDL-C than the adult population.

Insulin resistance HOMA-IR - a strong CM risk factor - varied from 2.4 to 4.5 with increasing obesity from in the last BMI quartile (Fig. 1) within our group, and the lifestyle intervention reduced the index from 3.5 to 2.6. Those values correspond well to earlier reports in children, where values close to 3 are adequate for the pediatric population (Kurtoglu et al. 2010). The associations of HOMA-IR with the lipoprotein components, including inverse associations with HDL-C and apoAI, and positive associations with TG and (naturally AIP) were highly significant within our group, but we did not prove the significance of the relationships between BMI to TC, LDL-C and the apoB/apoAI ratio.

The question of how many obese children had probably higher $\mathrm{CM}$ risk with respect to TG/HDL-C ratio or apoB/apoAI ratio is, currently, resolvable using 
sequestration according to AIP. A total of $13.8 \%$ of boys and only $5.3 \%$ of girls within the entire group had highrisk values (Fig. 2). Of those high-risk children, $50 \%$ belonged to the 4th BMI quartile. When a normal Slovak population, aged 40 years, was examined for CM risk factors, $10 \%$ of women and $30 \%$ of men fell into the high-risk AIP category (Rašlová et al. 2011). In another group examined for clinical cardiovascular problems, $41 \%$ of women and $58 \%$ of men with positive angiological diagnoses had high risk (Frohlich and Dobiášová 2003). Evidently, the degree of risk increases with age and with respective risk factors. Other studies also show that AIP can be used to detect CM disorders even at relatively normal lipid levels (Dobiášová et al. 2001).

\section{Conclusions}

AIP, apoB/apoAI and HOMA-IR are complementary in $\mathrm{CM}$ risk prognosis among overweight/obese children. AIP may have higher prognostic value due to its strong relation to both glycid metabolism and lipoprotein metabolism. Using biomarkers in overweight/obese children enables us to provide a more detailed description of the CM risk profile in plasma and to monitor the effects of various interventions. Applying a proper dietary and exercise regime during a spa treatment, even a short-term one, could substantially influence the future prognosis of the children with respect to both obesity reduction and CM risk.

\section{Conflict of Interest}

There is no conflict of interest.

\section{Acknowledgements}

The work has been supported by an independent research grant from Internal Grant Agency of Ministry of Health of the Czech Republic No. NT 14152-3/201.

\section{References}

CAMPOS H, GENEST JJ JR, BLIJLEVENS E, MCNAMARA JR, JENNER JL, ORDOVAS JM: Low density lipoprotein particle size and coronary artery disease. Arterioscler Thromb 12: 187-195, 1992.

CANAS JA, SWEETEN S, BALAGOPAL PB: Biomarkers for cardiovascular risk in children. Curr Opin Cardiol 28: 103-114, 2013.

DOBIÁŠOVÁ M, FROHLICH J: The plasma parameter log (TG/HDL-C) as an atherogenic index: correlation with lipoprotein particle size and esterification rate in apoB-lipoprotein-depleted plasma $\left(\mathrm{FER}_{\mathrm{HDL}}\right)$. Clin Biochem 34: 583-588, 2001.

DOBIÁŠOVÁ M, URBANOVÁ Z, RAUCHOVÁ H, ŠAMÁNEK M, FROHLICH J: High-density lipoprotein subclasses and esterification rate of cholesterol in children: effect of gender and age. Acta Paediatr 87: 918-923, 1998.

DOBIÁŠOVÁ M, RAŠLOVÁ K, RAUCHOVÁ H, VOHNOUT B , PTÁČKOVÁ K, FROHLICH J: Atherogenic lipoprotein profile in families with and without history of early myocardial infarction; fractional esterification rate of cholesterol in plasma depleted of apoB lipoproteins $\left(\mathrm{FER}_{\mathrm{HDL}}\right)$ and logarithmically transformed ratio of triglycerides to HDL-cholesterol. Physiol Res 50: 1-8, 2001.

DOBIÁŠOVÁ M, FROHLICH J, ŠEDOVÁ M, CHEUNG MC, BROWN BG: Cholesterol esterification and atherogenic index of plasma correlate with lipoprotein size and findings on coronary angiography. $J$ Lipid Res 52: 566-571, 2011.

FROHLICH J, DOBIÁŠOVÁ M: Fractional esterification rate of cholesterol and ratio of triglycerides to HDL-C are powerful predictors of positive findings on coronary angiography. Clin Chem 49: 1873-1880, 2003.

JEYARAJAH EJ, CROMWELL WC, OTVOS EJ: Lipoprotein particle analysis by nuclear magnetic resonance spectroscopy. Clin Lab Med 26: 847-870, 2006.

JUONALA M, VIIKARI JS, KÄHÖNEN M, SOLAKIVI T, HELENIUS H, JULA A, MARNIEMI J, TAITTONEN L, LAITINEN T, NIKKARI T, RAITAKARI OT: Childhood levels of serum apolipoproteins B and A-I predict carotid intima-media thickness and brachial endothelial function in adulthood: the cardiovascular risk in young Finns study. J Am Coll Cardiol 52: 293-299, 2008. 
KIKUCHI DA, SRINIVASAN SR, HARSHA DW, WEBBER LS, SELLERS TA, BERENSON GS: Relation of serum lipoprotein lipids and apolipoproteins to obesity in children: the Bogalusa Heart Study. Prev Med 21: 177-190, 1992.

KOBZOVÁ J, VIGNEROVÁ J, BLÁHA P, KREJČOVSKÝ L, RIEDLOVÁ J: The $6^{\text {th }}$ nationwide anthropological survey of children and adolescents in the Czech Republic in 2001. Centr Eur Public Health 12: 126-130, 2004.

KURTOĞLU S, HATIPOĞLU N, MAZICIOĞLU M, KENDIRICI M, KESKIN M, KONDOLOT M: Insulin resistance in obese children and adolescents: HOMA-IR cut-off levels in the prepubertal and pubertal periods. J Clin Res Pediatr Endocrinol 2: 100-106, 2010.

KWITEROVICH PO JR: Plasma lipid and lipoprotein levels in childhood. Ann NY Acad Sci 623: 90-107, 1991.

MOTYKOVA E, ZLATOHLAVEK L, PRUSIKOVA M, LANSKA V, CESKA R, VASICKOVA L, VRABLIK M: Lifestyle modification induced weight loss and changes of cardiometabolic risk factors including lowering of inflammatory response in obese children. Neuro Endocrinol Lett 32: 55-59, 2011.

MURGUÍA-ROMERO M, JIMÉNEZ-FLORES JR, SIGRIST-FLORES SC, ESPINOZA-CAMACHO MA, JIMÉNEZMORALES M, PIÑA E, MENDEZ-CRUZ AR, VILLALOBOS-MOLINA R, REAVEN GM: Triglyceride/high-density lipoprotein cholesterol ratio, insulin resistance, and cardio-metabolic risk in young men and women. J Lipid Res 54: 2795-2799, 2013.

MUSSO C, GRAFFIGNA M, SOUTELO J, HONFI M, LEDESMA L, MIKSZTOWICZ V, HONFI M, LEDESMA L, MIKSZTOWICZ V, PAZOS M, MIGLIANO M, SCHREIER LE, BERG GA: Cardiometabolic risk factors as apolipoprotein B, triglyceride/HDL-cholesterol ratio and C-reactive protein, in adolescents with and without obesity: cross-sectional study in middle class suburban children. Pediatr Diabetes 12: 229-234, 2011.

ONAT A, CAN G, KAYA H, HERGENC G: Atherogenic index of plasma (log10 triglyceride/high-density lipoproteidcholesterol) predicts high blood pressure, diabetes, and vascular events. J Clin Lipidol 4: 89-98, 2010.

RAŠLOVÁ K, DOBIÁŠOVÁ M, HUBÁČEK JA, BENCOVÁ D, SIVÁKOVÁ D, DANKOVÁ Z, FRANEKOVÁ J, JABOR A, GAŠPAROVIČ J, VOHNOUT B: association of metabolic and genetic factors with cholesterol esterification rate in HDL plasma and atherogenic index of plasma in a 40 years old slovak population. Physiol Res 60: 785-795, 2011.

REAVEN G: Insulin resistance and coronary heart disease in nondiabetic individuals. Arterioscler Thromb Vasc Biol 32: 1754-1759, 2012.

ŠAMÁNEK M, URBANOVÁ Z: Occurrence of overweight and obesity in 7,427 Czech children examined in 2006 (in Czech). Čes-slov Pediat 63: 120-126, 2008.

SELLERS EA, SINGH GR, SAYERS SM: Apo-B/AI ratio identifies cardiovascular risk in childhood: the Australian Aboriginal Birth Cohort study. Diab Vasc Dis Res 6: 94-99, 2009.

SIERRA-JOHNSON J, ROMERO-CORRAL A, SOMERS VK, LOPEZ-JIMENEZ F, WALLDIUS G, HAMSTEN A, HELLÉNIUS ML, FISHER RM: ApoB/apoA-I ratio: an independent predictor of insulin resistance in US nondiabetic subjects. Eur Heart J 28: 2637-2643, 2007.

SOLHPOUR A, PARKHIDEH S, SARRAFZADEGAN N, ASGARY S, WILLIAMS K, JUNGNER I, AASTVEIT A, WALLDIUS G, SNIDERMAN A: Levels of lipids and apolipoproteins in three cultures. Atherosclerosis 207: 200-207, 2009.

TAN MH, JOHNS D, GLAZER NB: Pioglitazone reduces atherogenic index of plasma in patients with type 2 diabetes. Clin Chem 50: 1184-1188, 2004.

THOMPSON A, DANESH J: Associations between apolipoprotein B, apolipoprotein AI, the apolipoprotein B/AI ratio and coronary heart disease: a literature-based meta-analysis of prospective studies. J Intern Med 259: 481-492, 2006.

TRESACO B, BUENO G, PINEDA I, MORENO LA, GARAGORRI JM, BUENO M: Homeostatic model assessment (HOMA) index cut-off values to identify the metabolic syndrome in children. J Physiol Chem 61: 381-388, 2005.

URBINA EM, KHOURY PR, MCCOY CE, DOLAN LM, DANIELS SR, KIMBALL TR: Triglyceride to HDL-C ratio and increased arterial stiffness in children, adolescents, and young adults. J Pediatr 158: 715-721, 2011. 
WALLDIUS G, JUNGNER I, HOLME I, AASTVEIT AH, KOLAR W, STEINER E: High apolipoprotein B, low apolipoprotein A-I, and improvement in the prediction of fatal myocardial infarction (AMORIS study): a prospective study. Lancet 358: 2026-2033, 2001. 